\title{
SCIENCE IN THE TRAP OF FRAUD AND CORRUPTION
}

The expression pathological science was introduced by I. Langmuir already in 1953. Since that time the investments into science and competition have been increasing and, consequently, the ground for scientific misconduct continues to expand. In this paper we discuss the scientific fraud in its multiple forms, such as falsification and fabrication of data, plagiarism, trading with papers and co-authorships, defrauding of funds, incorrect grant practices, etc. We identify the driving forces of misconduct as career pressure, anticipation of results, and working in the field where experiments are not precisely reproducible. The most visible fraud examples with their statistical distribution among countries and branches of science are provided. While serious cases of misconduct appear in countries with top research excellence in the process of seeking positions, awards and prizes, in the developing world the typical forms include self-plagiarism, conflict of interests in grant policy, bribery, and corruption. Finally, we elaborate on the policies supporting the research integrity.

Keywords: Ethics, fraud in science, comparative analysis, research integrity.

\section{Introduction}

This work is part of an effort to provide a typology of fraud and misconduct in science in Slovakia. Our observation should be relevant to other countries also. We reflect upon the status quo that is characterised by such phenomena as the exodus of the young scientific talent, poor qualifications of the new professors, cloning of the recently established universities, lack of transparency in grant-awarding practices, self-plagiarism, acquisition of sizeable new research infrastructures without securing adequate operational base, and the dismissal of the leading personnel due to financial mismanagement. Unless these phenomena are recognised and addressed, our research capabilities may suffer irreparable damage.

\section{Historical perspective}

A popular picture of the pre-1989 scientist, as an ethically coherent personality who would invest all his/her time and even own money into the struggle for acquiring new knowledge, did not correspond to reality. Great intellectual hoaxes paved the way of science, research, and discovery already in the previous centuries. For instance, in [1] we can find stories about a Frederic A. Cook who asserted that he had reached the North Pole in April 1908, almost one year before Admiral Robert E. Peary.
Another infamous example is Paul Schliemann, the grandson of the discoverer of Troy Heinrich Schliemann, who claimed to have proven the existence of Atlantis, using his own research and the documentation left by his grandfather [2].

Even the icons of physics and biology are not completely free of the stain of doubt. According to [3], Isaac Newton would introduce fudge factors in order to increase the predictive power of his work; Johann G. Mendel's results were too good to be true; Robert Millikan manipulated his measurements of the charge of electron to make the results more convincing, etc.

Irving Langmuir, Nobel laureate in chemistry, introduced the expression pathological science in December 1953. The talk was concerned with what he called "the science of things that aren't so". The lecture was transcribed and edited by R. N. Hall [4]. Langmuir analysed the results related to Davis-Barnes effect, so called N-rays and Mitogenetic rays, and he concluded that "these are the cases where there is no dishonesty...but people are tricked into false results by lack of understanding...wishful thinking or threshold interactions". Let us remind ourselves here of the symptoms of pathological science summarised by Langmuir [4]:

- The magnitude of the effect is substantially independent of the intensity of the causative agent.

- The effect is of magnitude that remains close to the limits of detectability; or, many measurements are necessary because of the very low statistical significance of the results.

- Claims of great accuracy.

\footnotetext{
* ${ }^{1}$ Stefan Luby, ${ }^{2}$ Martina Lubyova, ${ }^{3}$ Ladislav E. Roth

${ }^{1}$ Institute of Physics SAS, Bratislava, Slovakia

${ }^{2}$ Centre of Social and Psychological Sciences SAS, Bratislava, Slovakia

${ }^{3}$ Emeritus, Jet Propulsion Laboratory, California Inst. of Technol., Pasadena,USA

E-mail: stefan.luby@savba.sk
} 
- Fantastic theories contrary to experience.

- Criticisms are met by ad hoc excuses thought up on the spur of the moment.

- Ratio of supporters to critics rises up to somewhere near $50 \%$ and then falls gradually to oblivion.

Also other examples given by Langmuir, such as the extrasensory perception, flying saucers, etc., sound old today; nonetheless, new problems do keep emerging.

\section{Why does fraud appear?}

The road from pathological sciene, which does not suffer from dishonesty to real scientific fraud is analysed by Park in his Voodoo Science [5]. He says: "What may begin as honest error, however, has a way of evolving through almost imperceptible step...to fraud.” These steps are junk science, pseudoscience, and, finally, fradulent science. On this road there is less and less supporting evidence and more and more self-delusion. Finaly the thin line between foolishness and fraud is crossed.

The field of science is nowadays endowed with sizeable investments that inhibit the pathological effects and processes of the new type from inside the scientific circles, but also from outside. We can speak about the rent-seeking behaviour.

Governments have been supporting research and development systematically since the end of WW2 as a consequence of the decisive role science played in winning the war. (Examples of the scientific contributions applied at the battlefields are radar, nuclear weapons, encryption machines, armours, medicaments, etc.) In the United States a program of the government suport of science was formulated by Vannevar Bush, the science advisor to the US President in WW2. Bush's arguments and recommendations are contained in the document entitled "Science, the Endless Frontier". According to [6], the three motives active behind the scientific fraud are as follows: (a) the perpetrators are under career pressure; (b) they know or they think they know the answer to the problem being solved: accordingly, they attempt to shorten the road to fame and glory ${ }^{1}$; and (c) researchers often work in the fields where experiments are not precisely reproducible. This situation gives rise to the appearance of fraud in biomedicine, psychology, nanoscience, etc.

Nanoscience studies the intermediate state of matter between molecules and crystals where the primary quality transforms into a secondary one in a process of chaotic transition. The diversity of structures in the nanoworld is not studied or even cannot be any time studied thoroughly. Thus, it happens that nanotechnology is labelled as the alchemy of the 21 st century [7]. It is criticised that published articles are often "polished narratives, which convey that everything went according to plan" [8]. Therefore,

\footnotetext{
${ }^{1}$ It is noteworthy that at certain level of knowledge the discoveries or inventions, e.g. giant magnetoresistance or semiconductor laser, appeared independently in the same period at different places.
}

it is not surprising that the initiative for the reproducibility in nanotechnology comes in the foreground [9].

\section{Classification of misconduct in science}

As follows from [6] and [10] and from our own experience, the basic forms of misconduct in science can be classified as follows: (a) Fraud - falsification and fabrication of data, plagiarism and self-plagiarism; (b) Trading with publications including papers, citations and co-authorships, multiplication of journals and conferences; (c) Embezzlement of funds or deformed grant practices; (d) Science as playground for fraudulent business practices, e.g. with pharmaceuticals and dietary supplements.

Falsification means manipulation of research materials, equipment, processes, changing or omitting data or results. Fabrication includes making up data or results and recording or reporting them. Plagiarism means appropriation of another person's ideas, results or words without giving him/her due credit.

\section{Most visible fraud examples in the developed world}

In this section we provide a qualitative overview of the fraudulent behaviour in science by giving the examples of selected infamous cases [6, 11]. Among them, a considerable attention was paid to the so-called cold fusion (M. Fleischmann, S. Pons, Toyota), the announcement of new element 118 at Lawrence Livermore National Laboratory, where V. Ninov was supposed to fabricate data, or to the "discoveries" by J. H. Schön at Bell Laboratories, who falsified results in 17 publications including those in Nature and Science. Before the scandal was disclosed, he was called the Tiger Woods of physics. In the field of psychology, among the most visible cases was that of J. Förster from the University of Amsterdam. The examination committee concluded that the patterns in published papers were statistically impossible. At the time he was granted a prestigious appointment as the Alexander von Humboldt Professor at the Ruhr University, Bochum, with grant funds of approximately 5 million Euros. The reaction of the president of the Humboldt foundation was disappointing [12]. E. A. K. Alsabti, born in Iraq, is considered to be among the top plagiators. He picked articles from obscure journals, changed their titles and sent them under his own name to other obscure journals [11]. There is also a Nobel laureate, D. Baltimore, who has been involved in the fraudulent publication by one of his collaborators [11].

In order to proceed to a more quantitative overview, we quote the statistics of 48 notable misconduct cases in Table 1 [13]. It can be seen that the fraud flourishes mostly at top research units in the countries with top research excellence, where the motivation is strong in the quest for prestigious positions and grants. This is obviously not the case of Slovakia. The European 
Commission evaluated the scientific excellence in Europe [14], based on a simple algorithm using indicators related to ERC grants, patenting, ranking of universities, and the most highly cited papers. According to this evaluation, the EU average score was 48 , while that of the Netherlands was 79 , Germany 63 , Czech Republic 30, and Slovakia 18.

Ranking of countries in notable scientific misconduct cases Table 1

\begin{tabular}{|l|l|l|l|}
\hline Country & No. of cases & Country & No. of cases \\
\hline Canada & 1 & Norway & 2 \\
\hline China & 1 & Romania & 2 \\
\hline Denmark & 1 & Saudi Arabia & 1 \\
\hline Germany & 4 & South Africa & 1 \\
\hline Great Britain & 4 & Republic of Korea & 1 \\
\hline Israel & 1 & Spain & 2 \\
\hline Japan & 5 & Switzerland & 1 \\
\hline Netherlands & 3 & USA & 18 \\
\hline
\end{tabular}

Source: [13]

\section{Publication bazaar}

A similar expression was used in [10] to characterise the situation in fast developing countries, esp. in China. The research capacity of China is estimated to be about 1 million full-time equivalents (FTE). This represents a quantitative growth that opens the door also to various phenomena in terms of ethics. The publication business is flourishing, the gold standard being a paper in a top journal. Reportedly, the prize for co-authorship can be as high as 25000 USD. Papers can be edited without proper experiments. Adhering to the "tradition of leaps" China strives to make a major move ahead also in science. However, in this field the way to success is slow and bound by the historical developments. For example, by analysing the Nobel prizes granted for physics, we can show that at present the position of the United States (winning about half of all prizes) is rather stable, while the UK is going down and Germany with Japan are slowly rising. At the same time, no positive shift in the developing world is observed. The only positive tendencies in the developing world are driven through double affiliations, such as, for example, India or Taiwan with the UK or USA, etc. It should be mentioned, however, that the fast growth in China and India is largely behind the quantitative growth of world publications that continue to be exponential (since 1900); whereas the time needed for duplication of the world number of papers is 11.8 years.

\section{The problems in central and eastern Europe, including Slovakia}

Among the central problems in the CEE region we consider the prevalence of quantity over quality. This is caused, inter alia, by the plagiarism that occurs at all levels of scientific work, including at the early stages of earning the diplomas. Self-plagiarism, multiplication of publications, and mutual co-authorships are quite common. The factors that contribute to these phenomena are the strong focus on scientometric evaluations, many grants with under-threshold financing, pressure for acknowledgements, etc. For example, it follows from our not yet published analysis that in the CEE there are on average more authors per paper than in the Western Europe. However, not all CEE countries have a similar access to the solution of these problems. E.g. Poland developed already four systems for the control of plagiarism [15].

A qualitatively new situation in CEE has emerged due to the availability of the EU structural funds. In this respect, it is worth attention to read in the paper [16]:"A scientific oligarchy with close ties to policymakers writes the rules for the transfer of unprecedented amounts of public money into (semi-) private firms purchasing overpriced, duplicated or even useless equipment”. It is assumed that the percentage of funds that were involved in corrupt activities is > $20 \%$ [17], but this is a very conservative estimation.

In Slovakia the growth of publications does not follow the world trends, which we think is not a critical problem. The number of citations is growing due to the new phenomenon of massive quotations by the Chines researchers (mainly in the natural sciences), more careful individual record-keeping, new databases such as Scopus, or incorporation of conference proceedings into monitoring process. A serious problem in the $\mathrm{CEE}$ is the low level of patenting. In order to illustrate the gravity of the problem, it is enough to note that Austria has more patents that the whole CEE [18]. In addition to the common CEE factors, the Slovak situation is characteristic by the institutionally embedded conflict of interests in grant agencies, whereas the evaluation of the projects has to be done by the members of the small research community.

\section{Closing Remarks}

The twentieth century was not a century of dramatic increase of fraud, rather of its increased exposure. The future in this field is also linked to the processes of globalised access to information and more transparent environment. One can no longer assume the misconduct cases to be isolated phenomena while that majority of them will never be disclosed. It is assumed that the rise of open publication on the internet will be favourable for the disclosure of misconduct [11]. In electronic publications the readership is broader and the access is simpler. This enables the not-cited 
authors to detect and protest various cases. Also the pressures to condense text ("these data are not shown here") disappear.

The most crucial role in the fight against the fraudulent behaviour in science has to be played by institutions. Their responses, the setting of rules, and their enforcement are central. However, the responses by senior scientists and administrators have not proven to provide useful models for curbing the negative phenomena and practices described in this paper.

As examples of institutional attempts to deal with fraudulent behaviour let us mention the approach at Caltech [6] where the consecutive steps are: removal from the project, letter of reprimand, special monitoring of future work, probation or suspension, salary or rank reduction, and termination of employment. The Chinese Academy of Sciences responds to the "publication bazaar" by its program of moral integrity [10]. European Commission issued a Code of Conduct in nanoscience and nanotechnology [19], etc.

The Slovak scientific community has to pay more attention to the problems of fraud, misconduct, and integrity of science. Slovakia is lagging behind in this field, likewise in several others areas, including the scientific excellence. Otherwise a legitimate question can be asked as to the extent to which our science can be self-correcting, which is bordering on the issues of self-governance in science.

\section{References}

[1] SILVERBERG, R.: Scientists and Scoundrels. Lincoln: London: University of Nebraska Press, 2007, p. 108. ISBN 13 978-0-80325989-8.

[2] ibid, p. 163.

[3] BROAD, W., WADE, N.: Betrayers of the Truth. New York: Simon \& Schuster, 1982, p. 23. ISBN 0-671-44769-6.

[4] LANGMUIR, I.: Pathological Science: Scientific Studies Based on Non-existent Phenomena. Edited by R. N. Hall. Speculations in Science and Technology, 1985, 8, 2, 77-94.

[5] PARK, R. L: Voodoo Science. The Road from Foolishness to Fraud. Oxford: Oxford University Press, 2000, p. 10. ISBN 0-19-513515-6.

[6] GOODSTEIN, D.: On Fact and Fraud. Princeton: Oxford: Princeton University Press, 2010, p. 3, p. 64, 29-106, p. 135. ISBN 978-0-691-13966-1.

[7] McCARTHY,W.: Hacking Matter, http://www.wilmccarthy.com/hm.htm

[8] MUECK, L.: Report the awful Truth. Nature Nanotechnology, 2013, 4, 10, 693-695.

[9] Joining the reproducibility initiative. Editorial. Nature Nanotechnology, 2014, 9 (Dec.), 949.

[10] HVISTENDAHL, M.: China’s Publication Bazaar. Science, 2013, 342, 6162, 1035-1039.

[11] JUDSON, H. F.: The Great Betrayal: Fraud in Science. Orlando: Harcourt Inc., 2004, p. 151, p. 109, p. 191, p. 325. ISBN 0-15100877-9.

[12] SCHWARZ, H.: Honesty in Science - a thing of Past? Humboldt Kosmos, 2015, No. 104, p. 17.

[13] https://en.wikipedia.org/wiki/Scientific_misconduct

[14] EUROPEAN COMISSION: Research and Innovation Performance in EU Member States and Associated Countries. Edited by J. Stierna, and P. Vigier: Brussels: DG for Research and Innovation, 2013, p. 5. ISBN 978-92-79-22832-2.

[15] http://www.rsc.org/chemistryworld/2013/10/poland-gets-serious-plagiarism

[16] TOMASKA, L., NOSEK, J.: Opinion: Science in a Small European Country. The Scientist, 28.1.2014.

[17] BALAZ, V.: www.aktuality.sk, April 27, 2014.

[18] STRAUSS, J.: Personal communication.

[19] EUROPEAN COMISSION: Commission Recommendation on a Code of Conduct for Responsible Nanosciences and Nanotechnologies Research. Brussels: DG for Research, EUR 23906, 2009, 21 p. ISBN 978-92-79-1-11605-6. 